\title{
Article
}

\section{Intelligent Temperature-Control of Drilling Fluid in Natural Gas Hydrate Formation by Nano-Silica/Modified n-Alkane Microcapsules}

\author{
Yubin Zhang ${ }^{1} \oplus$, Zhengsong Qiu ${ }^{1, *}$, Jiaxing Mu ${ }^{1}$, Yongle Ma ${ }^{2}$, Xin Zhao ${ }^{1}$, Hanyi Zhong ${ }^{1}$, Weian Huang ${ }^{1}$ \\ and Pengfei Guo ${ }^{1}$ \\ 1 School of Petroleum Engineering, China University of Petroleum (East China), Qingdao 266580, China; \\ upczhangyubin@126.com (Y.Z.); zhgw1027@163.com (J.M.); upczhao123@163.com (X.Z.); \\ upczhong1112@163.com (H.Z.); upcschooler@163.com (W.H.); upcbron0912@163.com (P.G.) \\ 2 Drilling Technology Research and Development Center, Bo-Xing Division of CNPC Offshore Engineering \\ Company Limited, Tianjin 300451, China; 15853291860@163.com \\ * Correspondence: B18020010@s.upc.edu.cn; Tel.: +86-0532-86983576
}

check for updates

Citation: Zhang, Y.; Qiu, Z.; Mu, J.; Ma, Y.; Zhao, X.; Zhong, H.; Huang, W.; Guo, P. Intelligent

Temperature-Control of Drilling Fluid in Natural Gas Hydrate Formation by Nano-Silica/Modified n-Alkane Microcapsules. Nanomaterials 2021, 11, 2370. https://doi.org/10.3390/ nano11092370

Academic Editor: Yoshio Bando

Received: 19 August 2021

Accepted: 10 September 2021

Published: 12 September 2021

Publisher's Note: MDPI stays neutral with regard to jurisdictional claims in published maps and institutional affiliations.

\begin{abstract}
Inhibiting hydrate decomposition due to the friction heat generated by the drilling tools is one of the key factors for drilling hydrate formation. Since the existing method based on chemical inhibition technology can only delay the hydrate decomposition rate, a phase-change microcapsule was introduced in this paper to inhibit, by the intelligent control of the drilling fluid temperature, the decomposition of the formation hydrate, which was microencapsulated by modified n-alkane as the core material, and nano-silica was taken as the shell material. Scanning electron microscope (SEM), size distribution, X-ray diffraction (XRD), and Fourier transform infrared spectrometer (FT-IR) were utilized to characterize the structural properties of microcapsules. Differential scanning calorimetry (DSC) spectra displayed that the latent heat was $136.8 \mathrm{~J} / \mathrm{g}$ in the case of melting enthalpy and $136.4 \mathrm{~J} / \mathrm{g}$ in the case of solidification enthalpy, with an encapsulation efficiency of $62.6 \%$. In addition, the prepared microcapsules also showed good thermal conductivity and reliability. By comparison, it was also proved that the microcapsules had good compatibility with drilling fluid, which can effectively control the temperature of drilling fluid for the inhibition of hydrate decomposition.
\end{abstract}

Keywords: microcapsule; modified n-alkane; nano-silica; hydrate formation; latent heat performance; intelligent temperature-control

\section{Introduction}

The huge resource reserves of natural gas hydrate have made the drilling and development of hydrate formation a research hotspot [1,2]. Hydrate mainly occurs under low temperature and high pressure in seabed formation, which puts forward a severe technical challenge to drilling engineering [3,4]. One of the key problems lies in the hydrate decomposition caused by the cutting heat of drilling tools at the long horizontal well section in hydrate formation, which causes the formation to lose skeleton support, leading to collapse and even geological disasters [5-7]. However, the existing technology only delays the hydrate decomposition rate to a certain extent by the addition of chemical treatment agent $[8,9]$ instead of changing the phase equilibrium temperature of hydrate, therefore, the formation hydrate will continuously decompose with the increase of temperature. In that case, the intelligent temperature-control of drilling fluid by phase change materials (PCMs) to inhibit hydrate decomposition is of significant research value.

In recent years, scholars have carried out a large amount of researches on PCMs, and the technology of temperature control has also been developed gradually by storing energy in advance through material phase transition and releasing it at a suitable temperature [10-13]. These PCMs are mainly divided into organic and inorganic compounds. 
Compared with organic PCMs, inorganic PCMs are usually characterized by lower cost, higher thermal conductivity, and subcooling $[14,15]$. However, organic PCMs has been more widely used because of their higher latent heat performance, and n-alkanes are one of the effective ones [16-18]. For example, polystyrene, melamine formaldehyde, and capric-stearic acid have been used to coat n-tetradecane and n-hexadecane [19-21]. Compared with these shell materials, nano-silica can better improve the thermal conductivity, showing good hydrophilicity $[22,23]$. Therefore, this paper proposed a new idea of inhibiting the decomposition of formation hydrate by phase change microcapsules, which were synthesized by interfacial polymerization using modified $n$-alkane as the core material and nano-silica formed by simultaneous hydrolysis and polycondensation of TEOS and APTS as the shell material.

The water depth in the vertical well section of hydrate formation exceeds $1000 \mathrm{~m}$, and the seabed temperature ranges from $2-4{ }^{\circ} \mathrm{C}$ [24]. As shown in Figure 1, microcapsules change phase to store cold energy by cooling from wellhead to seabed. When circulating to the horizontal well section, which contains the hydrate in the formation, the microcapsules release the cold energy to balance the heat generated during the drilling process to control the temperature of the drilling fluid, so as to inhibit the decomposition of formation hydrate. In this paper, the structural properties of microcapsules were characterized by SEM, size distribution, XRD, and FT-IR tests. The latent heat of microcapsules was obtained by measuring DSC spectra, and then the encapsulation efficiency was calculated. After that, the thermal conductivity and reliability of microcapsules were discussed. Moreover, to better simulate the field application effect, the thermoregulating performance and compatibility between microcapsules and drilling fluid were experimentally studied.



Figure 1. Schematic diagram of microcapsules intelligent temperature-control in hydrate formation (modified from [25]).

\section{Methodology}

\subsection{Materials}

Tetraethyl nano-silicate (TEOS) and 3-aminopropyl-triethoxysilane (APTS) were purchased from Aladdin Reagents (Shanghai, China). And N-tetradecane, n-hexadecane, fatty acid ester, Span 80, Tween 80, and ethanol were obtained from Sinopharm Chemicals (Beijing, China). In addition, nucleating agent SD-N and cementing agent SD-C were provided by Shida Chuangxin Technology Co., Ltd. (Dongying, China). Deionized water was made in the laboratory.

\subsection{Preparation of Nano-Silica/Modified n-Alkane Microcapsules}

Microcapsules were prepared by interfacial polymerization, of which modified nalkane was used as the core material, and nano-silica formed by simultaneous hydrolysis 
and polycondensation of TEOS and APTS was used as the shell material. In a typical preparation procedure (as shown in Figure 2), $10 \mathrm{~g}$ n-tetradecane, $25 \mathrm{~g}$ n-hexadecane, and $10 \mathrm{~g}$ fatty acid ester were mixed in a $100 \mathrm{~mL}$ three-necks flask, then the mixture was added with $0.68 \mathrm{~g}$ nucleating agent SD-N and stirred at $40^{\circ} \mathrm{C}$ for $4.5 \mathrm{~h}$. After that, with the increase of the temperature, $1.35 \mathrm{~g}$ cementing agent SD-C was added gradually. Then, the modified $\mathrm{n}$-alkane was obtained by continuous stirring for $7 \mathrm{~h}$, and $10 \mathrm{~g}$ modified $\mathrm{n}$-alkane and $1.2 \mathrm{~g}$ Span 80 were mixed in a beaker as the oil phase. The aqueous phase was obtained by mixing $100 \mathrm{~g}$ deionized water with $1.5 \mathrm{~g}$ Tween 80 . In a $250 \mathrm{~mL}$ three-necks flask, the oil phase and the aqueous phase were mixed and stirred $(500 \mathrm{rpm})$ at $55^{\circ} \mathrm{C}$ for the preparation of a stable oil/water $(\mathrm{O} / \mathrm{W})$ emulsion. Subsequently, $9.6 \mathrm{~g}$ TEOS was added slowly to the $\mathrm{O} / \mathrm{W}$ emulsion, which was followed by the addition of $2.4 \mathrm{~g}$ APTS to adjust the $\mathrm{pH}$ value. After stirring for $5 \mathrm{~h}$, the products were washed three times with ethanol before being dried at $45^{\circ} \mathrm{C}$ for $16 \mathrm{~h}$.

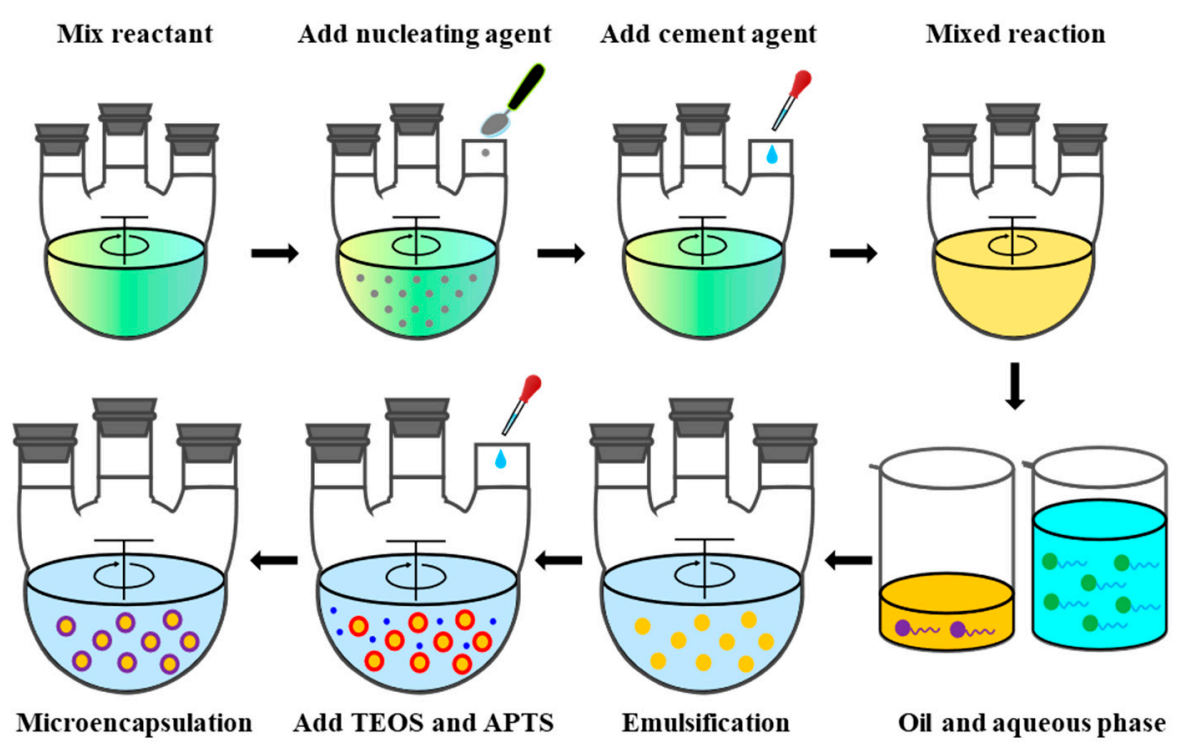

Figure 2. Typical preparation procedure of nano-silica/modified n-alkane microcapsules.

\subsection{Experimental Methods}

The microcapsules were performed at an accelerating voltage of $5 \mathrm{kV}$ by using a scanning electron microscope (SEM. Zeiss Sigma 300) after being coated with gold. Transmission electron microscope (TEM) photos were obtained by a JEOL JEM 2100 equipment after ultrasonic dispersion in deionized water. A Bettersize 2000 laser particle sizer was used for the determination of the size distribution. The microcapsules were dispersed in deionized water by ultrasound and added to the test dish drop by drop until the shading rate reached $10 \%$. X-ray diffraction (XRD) patterns were observed by using an Ultima IV equipment with the radiation voltage of $45 \mathrm{kV}$ and the current of $40 \mathrm{~mA}$ at a rate of $2^{\circ} / \mathrm{min}$ within the range of $10-80^{\circ}$. Fourier transform infrared spectrometer (FT-IR, Thermo Scientific Nicolet 10) was used for the observation of the structural characteristics of microcapsules within the range of $4000-400 \mathrm{~cm}^{-1}$. Differential scanning calorimetry (DSC) spectra was measured by using a TA Q2000 instrument. An approximately $5 \mathrm{mg}$ sample was used under nitrogen atmosphere at the heating rate ranging from $-50{ }^{\circ} \mathrm{C}$ to $50^{\circ} \mathrm{C}$. The thermal reliability of microcapsules was determined by DSC results after thermal cycling experiment. The microcapsules were put into an RTP incubator for heating/cooling in the range of $-50-50{ }^{\circ} \mathrm{C}$, which cycled for 10,20 , and 30 times, respectively.

A thermal conductivity measuring apparatus (TC3000E) was used for the measurement of the thermal conductivity of the microcapsules. The modified n-alkane was directly added to the sample cell and measured under liquid test mode. After being pressed into two cylinders, the powder microcapsules were tested by clamping the sensing probe be- 
tween the smooth surfaces. At least three experiments were performed in each group to ensure parallelism. The thermoregulating performance evaluation experiment was implemented in a reactor equipped with a hotplate stirrer. The microcapsule solution was added to the reactor, and then the hotplate stirrer was operated at the stirring speed of $200 \mathrm{r} / \mathrm{min}$ and the power of $120 \mathrm{~W}$ to simulate the release of the cutting heat of drilling tools. The temperature of the microcapsule solution was continuously recorded to characterize the thermoregulating performance. The rheology was tested by using six-speed viscometer (SRV11), and the filtration was measured by medium pressure filtration meter (SD4B). According to the standard of American Petroleum Institute (API), apparent viscosity (AV), plastic viscosity (PV), and yield point (YP) were calculated by the following formulas [26,27], respectively:

$$
\begin{gathered}
\mathrm{AV}=\varphi 600 / 2(\mathrm{mPa} \cdot \mathrm{s}) \\
\mathrm{PV}=\varphi 600-\varphi 300(\mathrm{mPa} \cdot \mathrm{s}) \\
\mathrm{YP}=(\varphi 300-\mathrm{PV}) / 2(\mathrm{~Pa})
\end{gathered}
$$

where $\varphi 600$ and $\varphi 300$ refer to the 600 and $300 \mathrm{rpm}$ readings of the six-speed viscometer.

\section{Results and Discussion}

\subsection{Synthesis of the Nano-Silica/Modified n-Alkane Microcapsules}

The modified n-alkane PCM with a suitable phase-change temperature was prepared to meet the temperature requirement of hydrate formation in Shenhu block, South China Sea [24]. The DSC spectra is shown in Figure 3. The melting temperature is $14.06{ }^{\circ} \mathrm{C}$ with a melting enthalpy of $216.1 \mathrm{~J} / \mathrm{g}$, and the solidification temperature is $14.01^{\circ} \mathrm{C}$ with a solidification enthalpy of $220.4 \mathrm{~J} / \mathrm{g}$. Microcapsules were synthesized by interfacial polymerization, of which modified n-alkane was used as the core material, and nanosilica formed by simultaneous hydrolysis and polycondensation of TEOS and APTS was used as the shell material. As shown in Figure 2, after the preparation of modified nalkanes, deionized water and emulsifier were added to form a stable oil-in-water $(\mathrm{O} / \mathrm{W})$ emulsion. APTS was used together with TEOS to adjust the $\mathrm{pH}$ value of the emulsion system through their inherent $\left[-\mathrm{NH}_{2}\right]$ groups, which release $\mathrm{OH}^{-}$, thereby facilitating the nucleophilic substitution and hydrolysis reaction of TEOS. Then, the polycondensation between hydrolysates $\mathrm{Si}-\mathrm{OH}$ produced $\mathrm{SiO}_{2}$, and nano-silica shell was formed by the continuous deposition and growth of $\mathrm{SiO}_{2}$ at the $\mathrm{O} / \mathrm{W}$ interface.

Latent heat performance is the key factor of PCMs, and encapsulation rate (R) and encapsulation efficiency (E) were used to characterize the latent heat properties of microcapsules prepared under different synthesis conditions, which can be expressed as follows [28,29]:

$$
\begin{gathered}
\mathrm{R}=\frac{\Delta \mathrm{Hm}, \text { Microcapsule }}{\Delta \mathrm{Hm}, \text { Modified } \mathrm{n}-\text { alkane }} \\
\mathrm{E}=\frac{\Delta \mathrm{Hm}, \text { Microcapsule }+\Delta \mathrm{H}, \text { Microcapsule }}{\Delta \mathrm{Hm}, \text { Modified } \mathrm{n}-\text { alkane }+\Delta \mathrm{Hs} \text {, Modified } \mathrm{n}-\text { alkane }}
\end{gathered}
$$

where $\Delta \mathrm{Hm}$, Microcapsule and $\Delta \mathrm{Hm}$, Modified $\mathrm{n}$-alkane refer to the melting enthalpy of the microcapsule and modified n-alkane, respectively; and $\Delta \mathrm{Hs}$, Microcapsule and $\Delta \mathrm{Hs}$, Modified n-alkane represent the solidification enthalpy of the microcapsule and modified n-alkane, respectively.

Table 1 shows the latent heat properties of microcapsules under different conditions. Encapsulation rate and efficiency of microcapsules were used to optimize the preparation conditions. The ratio of oil/water has an impact on the stability of the emulsion and the sphericity of the microcapsule. Neither too large nor too small ratio is conducive to achieving the oil-water balance and forming a stable $\mathrm{O} / \mathrm{W}$ emulsion. The introduction of emulsifier is available for a significant reduction of the surface tension of the oil-water interface. However, the emulsion droplets formed were easy to break under low dosage, 
and the subsequent $\mathrm{SiO}_{2}$ deposition would be blocked under high dosage; both phenomena restricted the effective coating of nano-silica shell. A slight increase in the ratio of Tween 80 may result in the increase of the Hydrophile Lipophilic Balance (HLB) value, which makes the droplets more stable in $\mathrm{O} / \mathrm{W}$ emulsion [30]. In the case that the core/shell ratio is large, nano-silica produced by hydrolysis and polycondensation will not be sufficient to completely cover the core material, resulting in the breakage of some microcapsules; while small core/shell ratio may lead to a shell that is too thick. Based on the above results, the latent heat of the nano-silica/modified n-alkane microcapsule is $136.8( \pm 2.0) \mathrm{J} / \mathrm{g}$ in the case of melting enthalpy and $136.4( \pm 1.8) \mathrm{J} / \mathrm{g}$ in the case of solidification enthalpy. It was calculated that the encapsulation rate and encapsulation efficiency were $63.3( \pm 0.9) \%$ and $62.6( \pm 0.8) \%$, respectively. The comparison of encapsulation efficiency of different PCMs is displayed in Table 2, and the results showed that the nano-silica/modified n-alkane microcapsules prepared in this paper showed high latent heat and encapsulation efficiency, proving a good thermal energy storage capacity.

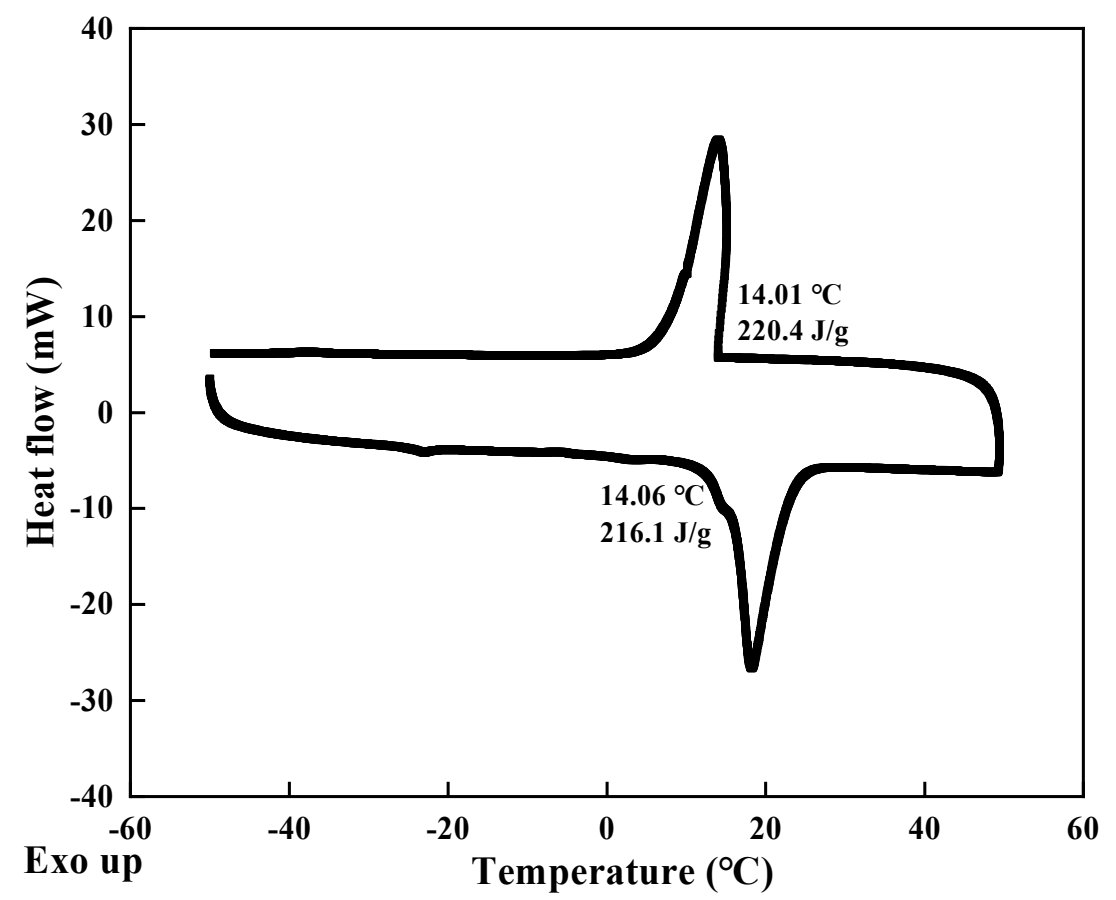

Figure 3. DSC spectra of prepared modified n-alkane.

Table 1. Latent heat properties of the microcapsules under different conditions.

\begin{tabular}{|c|c|c|c|c|c|c|c|c|c|}
\hline \multirow[b]{2}{*}{ Sample } & \multirow{2}{*}{$\begin{array}{c}\text { Oil/Water } \\
\text { Ratio } \\
(w / w)\end{array}$} & \multirow{2}{*}{$\begin{array}{c}\text { Emulsifier } \\
\text { Ratio } \\
\left(w_{\text {Span }} / w_{\text {Tween }}\right)\end{array}$} & \multirow{2}{*}{$\begin{array}{c}\text { Core/Shell } \\
\text { Ratio } \\
(w / w)\end{array}$} & \multicolumn{2}{|c|}{ Melting } & \multicolumn{2}{|c|}{ Solidification } & \multicolumn{2}{|c|}{ Encapsulation } \\
\hline & & & & $\begin{array}{c}\text { Temp } \\
\left({ }^{\circ} \mathrm{C}\right)\end{array}$ & $\begin{array}{c}\text { Enthalpy } \\
(\mathrm{J} / \mathrm{g})\end{array}$ & $\begin{array}{c}\text { Temp } \\
\left({ }^{\circ} \mathrm{C}\right)\end{array}$ & $\begin{array}{c}\text { Enthalpy } \\
(\mathrm{J} / \mathrm{g})\end{array}$ & $\begin{array}{c}\text { Rate } \\
(\%)\end{array}$ & $\begin{array}{c}\text { Efficiency } \\
(\%)\end{array}$ \\
\hline M1 & $10: 80$ & $1.5: 1.5$ & $10: 10$ & 13.94 & 72.6 & 13.91 & 73.0 & 33.6 & 33.4 \\
\hline M2 & $10: 100$ & $1.5: 1.5$ & $10: 10$ & 13.95 & 117.8 & 13.94 & 117.2 & 54.5 & 53.8 \\
\hline M3 & $10: 120$ & $1.5: 1.5$ & $10: 10$ & 13.88 & 93.4 & 13.89 & 93.1 & 43.2 & 42.7 \\
\hline M4 & $10: 100$ & $1.3: 1.3$ & $10: 10$ & 14.00 & 115.4 & 13.98 & 115.8 & 53.4 & 52.9 \\
\hline M5 & $10: 100$ & $1.7: 1.7$ & $10: 10$ & 13.97 & 108.7 & 13.96 & 107.9 & 50.3 & 49.6 \\
\hline M6 & $10: 100$ & $1.2: 1.5$ & $10: 10$ & 13.97 & 126.1 & 13.95 & 126.0 & 58.4 & 57.8 \\
\hline M7 & $10: 100$ & $1.0: 1.5$ & $10: 10$ & 13.92 & 114.4 & 13.90 & 114.1 & 52.9 & 52.3 \\
\hline M8 & $10: 100$ & $1.2: 1.5$ & $10: 8$ & 14.01 & 84.3 & 14.00 & 81.6 & 39.0 & 38.0 \\
\hline M9 & $10: 100$ & $1.2: 1.5$ & $10: 12$ & 13.99 & 136.8 & 13.95 & 136.4 & 63.3 & 62.6 \\
\hline M10 & $10: 100$ & $1.2: 1.5$ & $10: 14$ & 13.89 & 123.6 & 13.88 & 121.6 & 57.2 & 56.2 \\
\hline
\end{tabular}


Table 2. The comparison of encapsulation efficiency of different PCMs.

\begin{tabular}{cccc}
\hline Sample & Melting Enthalpy $(\mathbf{J} / \mathbf{g})$ & Encapsulation Efficiency (\%) & Ref. \\
\hline $\begin{array}{c}\text { Polystyrene } \\
\text { /n-tetradecane }\end{array}$ & 98.7 & 44.3 & {$[19]$} \\
$\begin{array}{c}\text { MF } \\
/ \text { n-tetradecane } \\
\text { polyHIPE }\end{array}$ & 100.3 & 44.2 & {$[20]$} \\
$/$ n-hexadecane \\
$\begin{array}{c}\text { CaCO } \\
/ \text { n-tetradecane }\end{array}$ & 143.4 & 56.3 & {$[31]$} \\
$\begin{array}{c}\text { Silica } \\
/ \text { modified n-alkanes }\end{array}$ & 58.5 & 25.9 & {$[32]$} \\
\hline
\end{tabular}

\subsection{Structural Properties}

The morphology of microcapsules was observed by using SEM and TEM, as shown in Figure 4. The synthesized microcapsules were in spherical shape with dense surface, most of which are in the particle size of $10 \mu \mathrm{m}$. As shown in the energy dispersion spectroscopy (EDS) spectrum in Figure 4c, since the core material contains no silicon element, the silicon on the surface of the microcapsules comes from nano-silica, indicating the successful coating. The results of TEM (as shown in Figure $4 \mathrm{~d}$ ) also proved that the microcapsules had good sphericity. Meanwhile, nano-silica was observed at the shell, which also indicated that the core material had been coated with nano-silica.
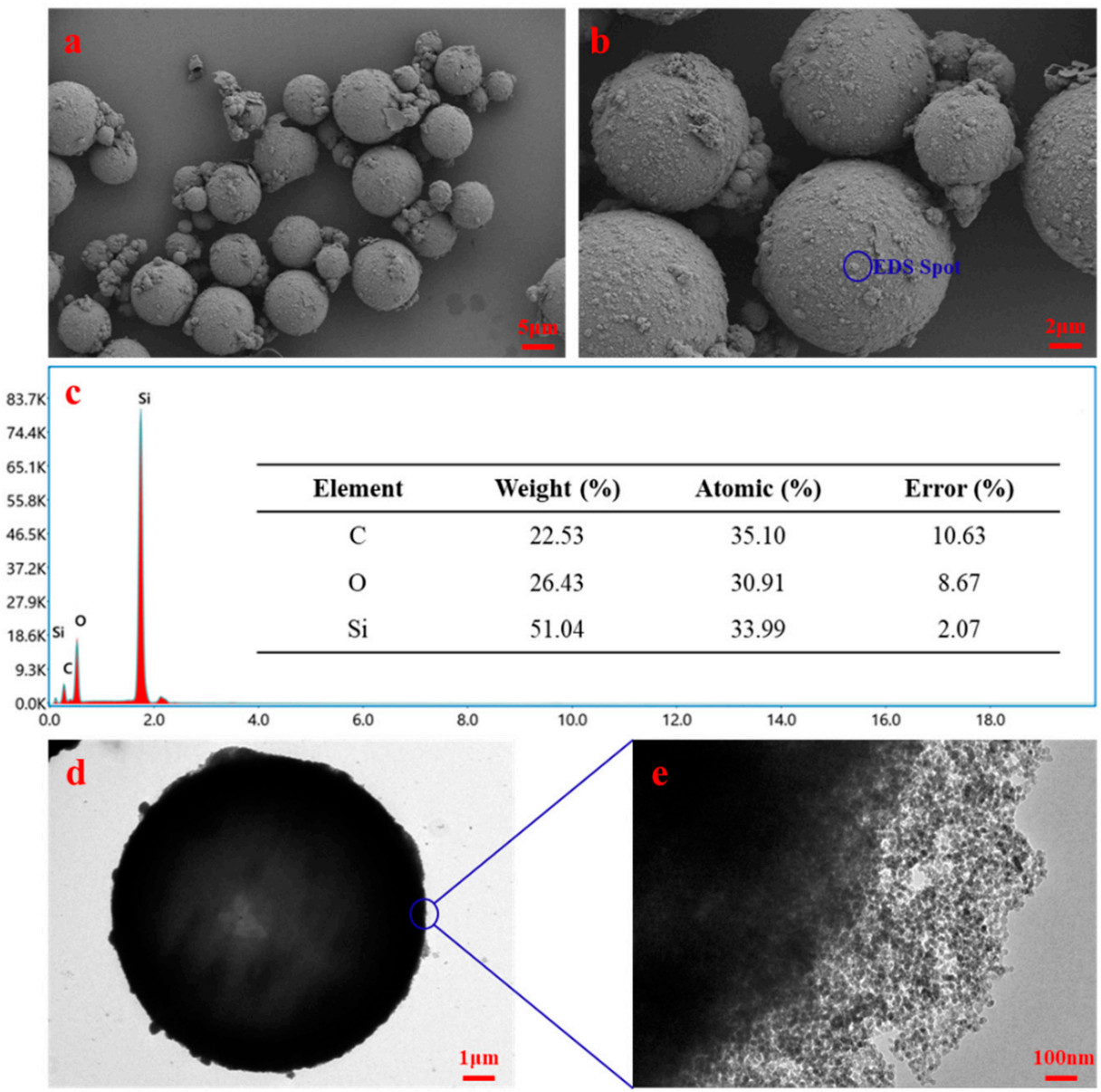

Figure 4. SEM photos (a,b), EDS spectrum (c), and TEM photos (d,e) of microcapsules.

Figure 5 displays the particle size distribution of microcapsules in deionized water, and the particle size distribution curve showed a single peak, which indicated that the microcapsule size was relatively uniform. The microcapsules with median particle size 
was $10.341 \mu \mathrm{m}$; most of them were distributed within the range of 5.324-28.054 $\mu \mathrm{m}$, which is consistent with the SEM test results. Meanwhile, the particle size also meets the screen requirements $(106 \mu \mathrm{m})$ for offshore drilling recovery.



Figure 5. Particle size distribution of microcapsules in deionized water.

The FTIR spectra of nano-silica, modified n-alkane, and microcapsule were shown in Figure 6. Nano silica was prepared by the hydrolysis and polycondensation of TEOS and APTS. The absorption peaks at $2923 \mathrm{~cm}^{-1}$ and $2856 \mathrm{~cm}^{-1}$ are considered as C-H stretching vibration of $-\mathrm{CH}_{3}$ and $-\mathrm{CH}_{2}$, which are also present in nano-silica due to the residue of reactants. Moreover, the absorption peak at $1462 \mathrm{~cm}^{-1}$ corresponds to $\mathrm{C}-\mathrm{H}$ bending vibration of $-\mathrm{CH}_{3}$, and the one at $721 \mathrm{~cm}^{-1}$ results from the $-\mathrm{CH}_{2}$ in-plane rocking vibration. In addition, the appearance of the peak at $1056 \mathrm{~cm}^{-1}$ of nano-silica and microcapsule is associated with $\mathrm{Si}-\mathrm{O}-\mathrm{Si}$ stretching vibration. No obvious new peak appears in the microcapsules. It can be seen from the above results that the modified n-alkanes are effectively coated by nano-silica. Figure 7 illustrates the XRD spectrum of microcapsules. A wide dispersion peak appears at $21^{\circ}$, indicating the amorphous structure of the produced nano-silica. Meanwhile, there is no characteristic peak in the spectrum of microcapsules because the modified n-alkanes have no liquid crystal under the test conditions.

\subsection{Thermal Conductivity and Reliability}

As organic PCM, the modified n-alkane has the inherent defect of low thermal conductivity. Figure 8 displays the thermal conductivity of different microcapsules and modified n-alkane. The average thermal conductivity of liquid modified n-alkane is only $0.1755 \mathrm{~W} / \mathrm{mK}$, which can be significantly improved by the coating with nano-silica. With the increase of nano-silica content, the thermal conductivity of microcapsules increases.

Meanwhile, the relationship between encapsulation efficiency and thermal conductivity under the same dosage of nano-silica was studied in Figure 9, and the results showed a good positive correlation $\left(\mathrm{R}^{2}>0.95\right)$. That may be because the higher the encapsulation efficiency, the less the residual voids in the microcapsules, leading to a higher thermal conductivity.

The thermal reliability of PCMs is the key factor to determine whether they can be recycled [28]. The DSC spectra of microcapsules after different thermal cycles are shown in Figure 10, and it was found that the more the cycle, the smaller the latent heat of microcapsules, indicating that a small number of microcapsules lost efficacy gradually. 
Compared with the microcapsules after 30 cycles, the melting enthalpy of the initially prepared microcapsules decreased by $9.1 \%$, that is, from $136.8 \mathrm{~J} / \mathrm{g}$ to $124.3 \mathrm{~J} / \mathrm{g}$, which indicates that the microcapsules had relatively good thermal stability.

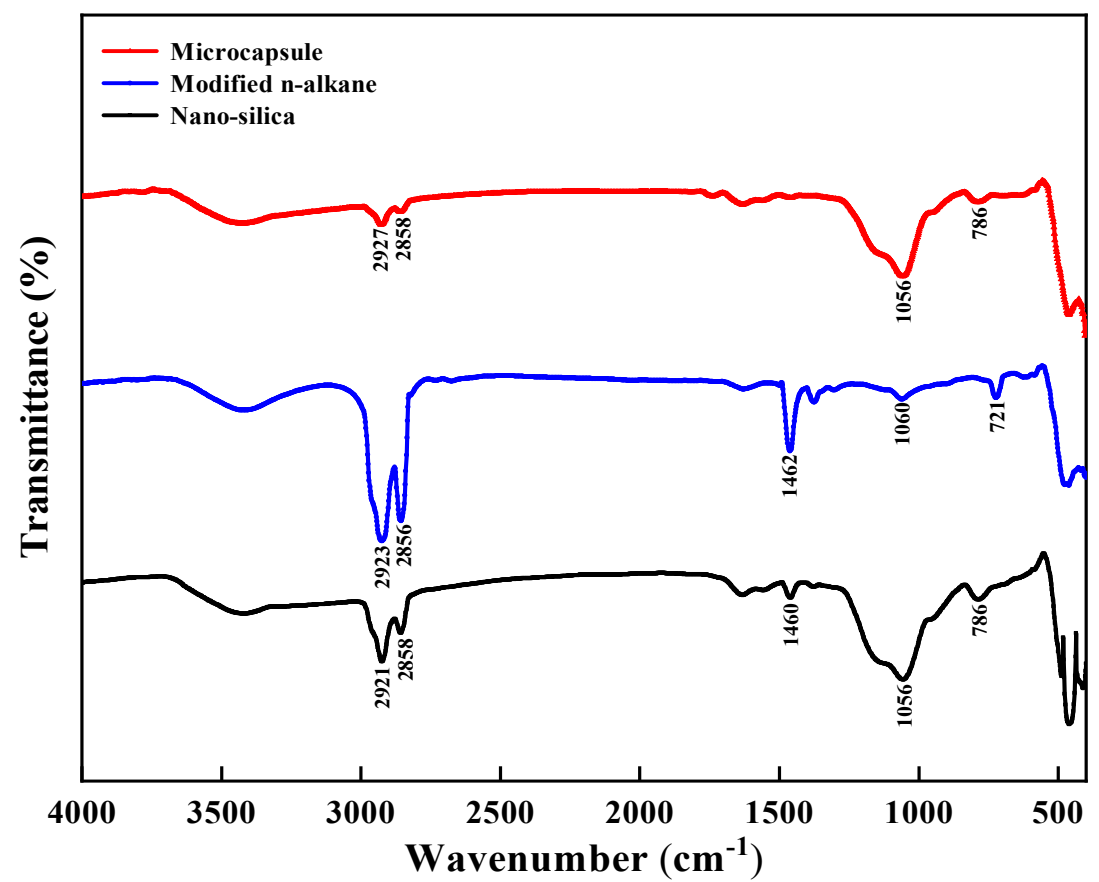

Figure 6. FTIR spectra of nano-silica, modified n-alkane and microcapsule.

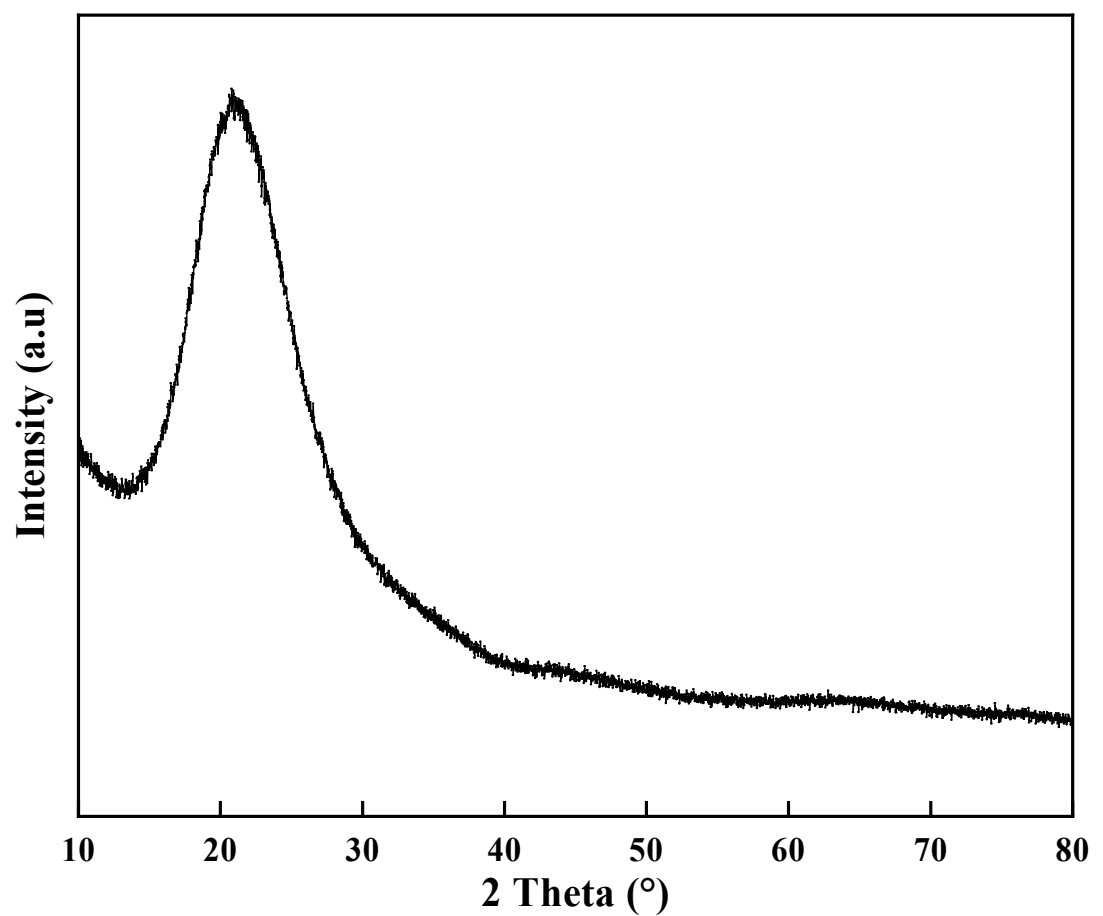

Figure 7. XRD spectrum of microcapsules. 


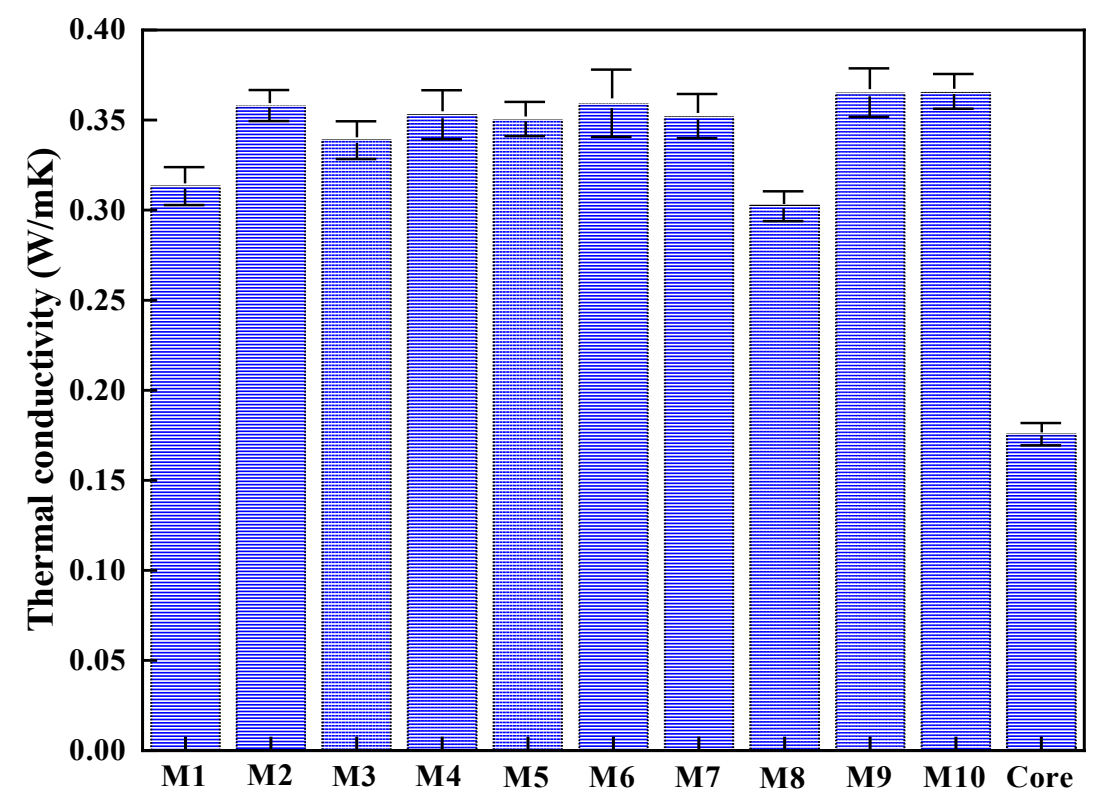

Figure 8. Thermal conductivity of different microcapsules and core material.



Figure 9. Relationship between encapsulation efficiency and thermal conductivity.

\subsection{Thermoregulating Performance and Compatibility with Drilling Fluid}

From wellhead to seabed, the phase-change microcapsules changed the phase to store energy by cooling and releasing the cold energy in the hydrate formation, thereby controlling the cutting heat released by drilling tools. By simulating the seabed temperature of $3^{\circ} \mathrm{C}$, the cold storage capacity of microcapsules was fully stored; after that, the temperature was increased to $14^{\circ} \mathrm{C}$ for the simulation of the temperature of hydrate formation. When the temperature rose to $14{ }^{\circ} \mathrm{C}$, the hotplate stirrer run for 30 minutes to simulate the cutting heat release by the drilling tools. Starting from $10{ }^{\circ} \mathrm{C}$, the solution temperature change was continuously recorded through a high-precision temperature sensor with the temperaturetime curves shown in Figure 11. Before reaching the phase transition temperature, the temperature-time curves of different solutions were basically coincident. After that, the 
solution containing microcapsules showed an obvious trend of temperature rise delay, and with the increase of dosage, the temperature control was more significant. Compared with the pure solution, the maximum temperature of the solution with $5 \mathrm{wt} \%$ microcapsules was only $14.9^{\circ} \mathrm{C}$ with a decrease of $1.8^{\circ} \mathrm{C}$, which showed good thermoregulating performance of microcapsules.

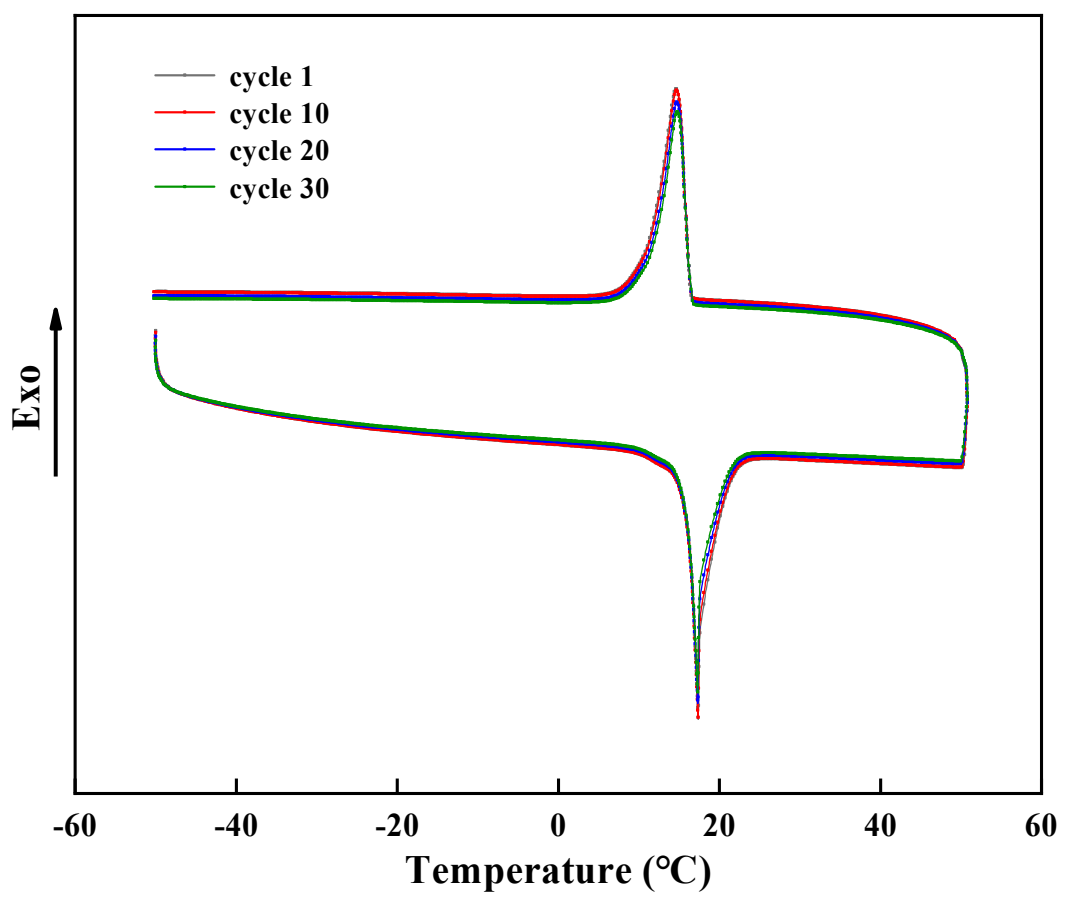

Figure 10. DSC spectra of different thermal cycles.

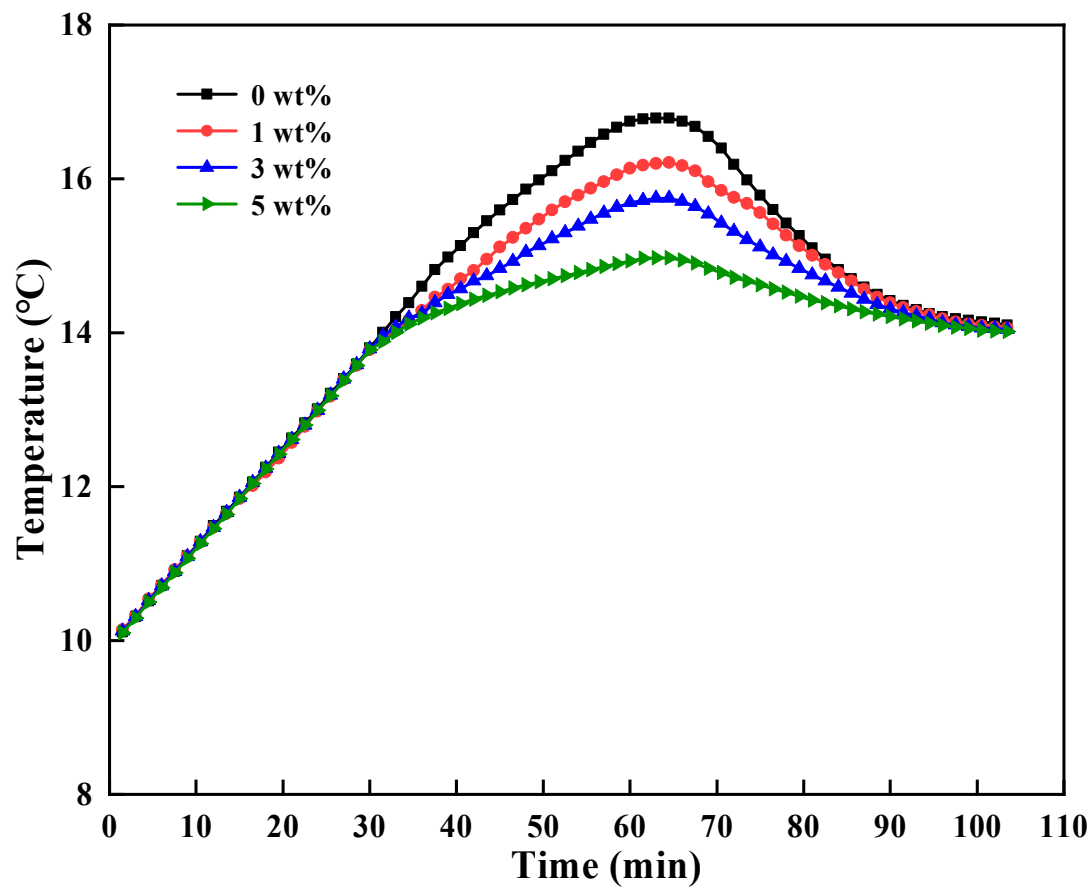

Figure 11. Temperature-time curves of different microcapsule solutions.

Water-based drilling fluid system has been used for hydrate formation drilling [24,25], and the microcapsules should have a good compatibility with drilling fluid in the practical application. Figures 12 and 13 show the basic properties of drilling fluid (previously 
constructed for drilling in hydrate formation [33]) with and without microcapsules, respectively. It is found from the results that the addition of microcapsules can increase the viscosity of drilling fluid, and the yield point to plastic viscosity remained at 0.5 , which is conducive to carrying cuttings and cleaning the bottom hole [34,35]. In addition, the addition of microcapsules had little effect on the density of drilling fluid, and there was no density difference between the upper and lower layers after standing for $72 \mathrm{~h}$, indicating the good solubility and settlement stability of microcapsules in drilling fluid. By comparison, the addition of $5 \mathrm{wt} \%$ microcapsules can reduce the filtration loss from $5 \mathrm{~mL}$ to $3.1 \mathrm{~mL}$, and it can significantly reduce the impact of filtrate invasion on the original formation, which was of great significance to maintain the wellbore stability of hydrate formation.

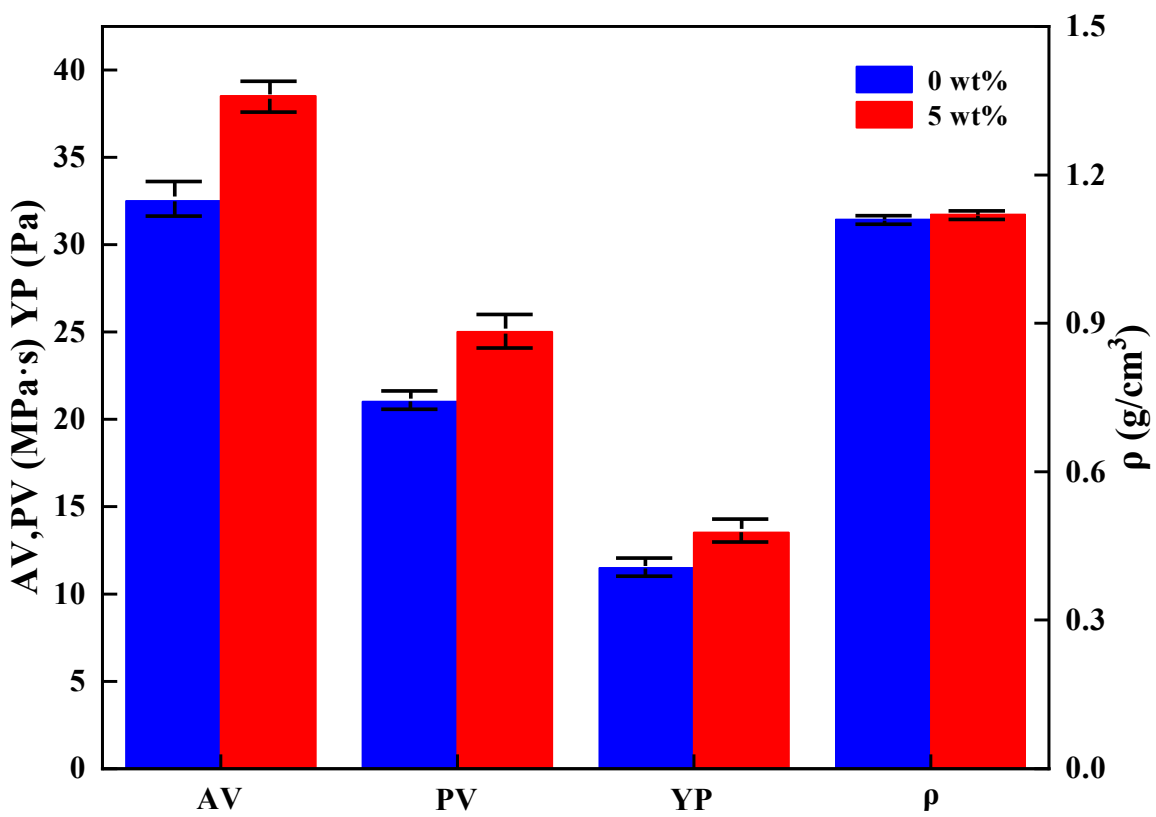

Figure 12. Rheological parameters and density of drilling fluid with or without microcapsules.

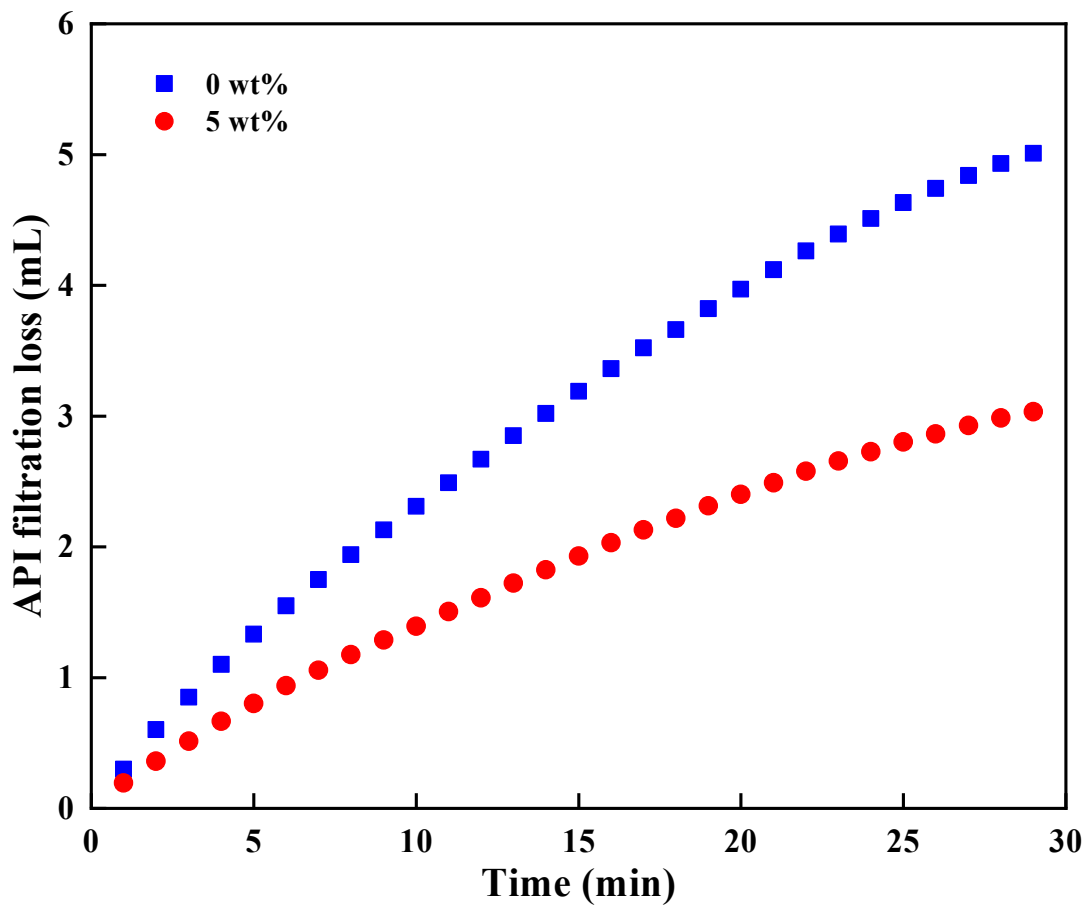

Figure 13. API filtration loss of drilling fluid with or without microcapsules. 


\title{
4. Conclusions
}

Microcapsules with modified n-alkane as core material and nano-silica formed by simultaneous hydrolysis and polycondensation of TEOS and APTS as shell material were synthesized by interfacial polymerization. The latent heat of the prepared microcapsules was $136.8 \mathrm{~J} / \mathrm{g}$ in the case of melting enthalpy and $136.4 \mathrm{~J} / \mathrm{g}$ in the case of solidification enthalpy at the encapsulation efficiency as $62.6 \%$. The microcapsules were in spherical shape, and the median particle size was $10.341 \mu \mathrm{m}$, which was conducive to the recycling through the screen. In addition, the coating of nano-silica improved the thermal conductivity of the modified n-alkane. After 30 cycles, the microcapsules still exhibited good thermal reliability. With the addition of $5 \mathrm{wt} \%$ microcapsules, the solution showed good thermoregulating performance, which was of great significance for the inhibition of formation hydrate decomposition. Moreover, the microcapsules showed good compatibility with water-based drilling fluid. Therefore, this paper proposed a new idea for the inhibition of formation hydrate decomposition by intelligent temperature control of drilling fluid, and developed a phase-change microcapsule available to be applied to hydrate drilling engineering, which has guiding significance for the design of drilling fluid in hydrate formation.

\begin{abstract}
Author Contributions: Conceptualization, Y.Z. and Z.Q.; methodology, Y.Z.; software, J.M.; validation, J.M., X.Z. and H.Z.; formal analysis, H.Z.; investigation, Y.M.; resources, P.G.; data curation, Y.Z.; writing-original draft preparation, H.Z.; writing—review and editing, X.Z.; visualization, W.H.; supervision, Z.Q.; project administration, Z.Q.; funding acquisition, Z.Q. All authors have read and agreed to the published version of the manuscript.

Funding: This research was funded by the National Natural Science Foundation of China (Major Program, 51991363), CNPC's Major Science and Technology Projects (ZD2019-184-003), the National Natural Science Foundation of China (51804331) and the Postgraduate Innovation Projects (YCX2020030).
\end{abstract}

Conflicts of Interest: The authors declare no conflict of interest.

\section{References}

1. Wan, L.; Zang, X.; Fu, J.; Zhou, X.; Lu, J.; Guan, J.; Liang, D. Formation of a Low-Density Liquid Phase during the Dissociation of Gas Hydrates in Confined Environments. Nanomaterials 2021, 11, 590. [CrossRef]

2. Kvenvolden, K.A. Methane hydrate in the global organic carbon cycle. Terra Nova 2010, 14, 302-306. [CrossRef]

3. Sloan, E.D. Clathrate Hydrates of Natural Gases; Marcel Dekker, INC.: New York, NY, USA, 1998.

4. Sloan, E.D. Fundamental principles and applications of natural gas hydrates. Nature 2003, 426, 353-363. [CrossRef] [PubMed]

5. Colwell, F.; Matsumoto, R.; Reed, D. A review of the gas hydrates, geology, and biology of the Nankai Trough. Chem. Geol. 2004, 205, 391-404. [CrossRef]

6. Konno, Y.; Fujii, T.; Sato, A.; Akamine, K.; Naiki, M.; Masuda, Y.; Yamamoto, K.; Nagao, J. Key Findings of the World's First Offshore Methane Hydrate Production Test off the Coast of Japan: Toward Future Commercial Production. Energy Fuels 2017, 31, 2607-2616. [CrossRef]

7. Yu, T.; Guan, G.; Abudula, A. Production performance and numerical investigation of the 2017 offshore methane hydrate production test in the Nankai Trough of Japan. Appl. Energy 2019, 251, 113338. [CrossRef]

8. Sultan, N.; Cochonat, P.; Foucher, J.P.; Mienert, J.; Sejrup, H.P. Effect of gas hydrates melting on seafloor slope instability. Mar. Geol. 2004, 213, 379-401. [CrossRef]

9. Hardwick, J.S.; Mathias, S.A. Masuda's sandstone core hydrate dissociation experiment revisited. Chem. Eng. Sci. 2018, 175, 98-109. [CrossRef]

10. Hawlader, M.; Uddin, M.S.; Khin, M.M. Microencapsulated PCM thermal-energy storage system. Appl. Energy 2003, 74, 195-202. [CrossRef]

11. Jamekhorshid, A.; Sadrameli, S.M.; Farid, M. A review of microencapsulation methods of phase change materials (PCMs) as a thermal energy storage (TES) medium. Renew. Sustain. Energy Rev. 2014, 31, 531-542. [CrossRef]

12. Keshteli, A.N.; Sheikholeslami, M. Nanoparticle enhanced PCM applications for intensification of thermal performance in building: A review. J. Mol. Liq. 2019, 274, 516-533. [CrossRef]

13. Xiong, X.; Venkataraman, M.; Yang, T.; Kucerova, K.; Militky, J.; Yang, K.; Zhu, G.; Yao, J. Transport Properties of Electro-Sprayed Polytetrafluoroethylene Fibrous Layer Filled with Aerogels/Phase Change Materials. Nanomaterials 2020, 10, 2042. [CrossRef] [PubMed]

14. Konuklu, Y.; Unal, M.; Paksoy, H.O. Microencapsulation of caprylic acid with different wall materials as phase change material for thermal energy storage. Sol. Energy Mater. Sol. Cells. 2014, 120, 536-542. [CrossRef] 
15. Mahmoudi, B.; Naeiji, P.; Varaminian, F. Study of tetra-n-butylammonium bromide and tetrahydrofuran hydrate formation kinetics as a cold storage material for air conditioning system. J. Mol. Liq. 2016, 214, 96-100. [CrossRef]

16. Paradela, F.; Queimada, A.J.; Marrucho, I.M.; Neto, C.P.; Coutinho, J.A.P. Modeling the thermal conductivity of pure and mixed heavy n-alkanes suitable for the design of phase change materials. Int. J. Thermophys. 2005, 26, 1461-1475. [CrossRef]

17. Vélez, C.; Khayet, M.; De, Z. Temperature-dependent thermal properties of solid/liquid phase change even-numbered n-alkanes: N-Hexadecane, n-octadecane and n-eicosane. Appl. Energy 2015, 143, 383-394. [CrossRef]

18. Aksoy, S.A.; Alkan, C.; Tözüm, M.S.; Demirbağ, S.; Anayurt, R.A.; Ulcay, Y. Preparation and textile application of poly (methyl methacrylate-co-methacrylic acid)/n-octadecane and n-eicosane microcapsules. J. Text. Inst. 2017, 108, 30-41. [CrossRef]

19. Fang, Y.; Yu, H.; Wan, W.; Gao, X.; Zhang, Z. Preparation and thermal performance of polystyrene/n-tetradecane composite nanoencapsulated cold energy storage phase change materials. Energy Convers. Manag. 2013, 76, 430-436. [CrossRef]

20. Wei, K.; Wang, Y.; Ma, B. Effects of microencapsulated phase change materials on the performance of asphalt binders. Renew. Energy 2019, 132, 931-940. [CrossRef]

21. Sarier, N.; Onder, E.; Ozay, S.; Ozkilic, Y. Preparation of phase change material-montmorillonite composites suitable for thermal energy storage. Thermochim. Acta 2011, 524, 39-46. [CrossRef]

22. Dil, E.J.; Virgilio, N.; Favis, B.D. The effect of the interfacial assembly of nano-silica in poly (lactic acid)/poly (butylene adipateco-terephthalate) blends on morphology, rheology and mechanical properties. Eur. Polym. J. 2016, 85, 635-646.

23. Shiraz, H.; Peake, S.J.; Davey, T.; Cameron, N.R.; Tabor, R.F. Preparation of novel film-forming armoured latexes using silica nanoparticles as a pickering emulsion stabiliser. J. Colloid Interface Sci. 2018, 528, 289-300. [CrossRef]

24. Qin, X.; Liang, Q.; Ye, J.; Qiu, H.; Xie, W.; Liang, J.; Lu, J.; Lu, C.; Lu, H.; Kuang, Z.; et al. The response of temperature and pressure of hydrate reservoirs in the first gas hydrate production test in South China Sea. Appl. Energy 2020, 278, 115649. [CrossRef]

25. Ye, J.; Qin, X.; Xie, W.; Lu, H.; Ma, B.; Qiu, H.; Liang, J.; Lu, J.; Kuang, Z.; Lu, C.; et al. Main progress of the second gas hydrate trial production in the South China Sea. Geol. China 2020, 47, 557-568, (In Chinese with English abstract).

26. Elkatatny, S. Enhancing the rheological properties of water-based drilling fluid using micronized starch. Arab. J. Sci. Eng. 2019, 44, 5433-5442. [CrossRef]

27. Zhong, H.; Kong, X.; Chen, S.; Grady, B.P.; Qiu, Z. Preparation, characterization and filtration control properties of crosslinked starch nanospheres in water-based drilling fluids. J. Mol. Liq. 2021, 325, 115221. [CrossRef]

28. Salunkhe, P.B.; Shembekar, P.S. A review on effect of phase change material encapsulation on the thermal performance of a system. Renew. Sustain. Energy Rev. 2012, 16, 5603-5616. [CrossRef]

29. Liu, Z.; Chen, Z.; Yu, F. Preparation and characterization of microencapsulated phase change materials containing inorganic hydrated salt with silica shell for thermal energy storage. Sol. Energy Mater. Sol. Cells 2019, 200, 110004. [CrossRef]

30. Fang, Y.; Wei, H.; Liang, X.; Wang, S.; Liu, X.; Gao, X.; Zhang, Z. Preparation and thermal performance of silica/n-tetradecane microencapsulated phase change material for cold energy storage. Energy Fuels 2016, 30, 9652-9657. [CrossRef]

31. Mert, H.H. PolyHIPE composite based-form stable phase change material for thermal energy storage. Int. J. Energy Res. 2020, 44, 6583-6594. [CrossRef]

32. Fang, Y.; Zou, T.; Liang, X.; Wang, S.; Liu, X.; Gao, X.; Zhang, Z. Self-assembly synthesis and properties of microencapsulated n-tetradecane phase change materials with a calcium carbonate shell for cold energy storage. ACS Sustain. Chem. Eng. 2017, 5, 3074-3080. [CrossRef]

33. Qiu, Z.; Zhang, Y.; Zhao, X.; He, Q.; Chen, Z.; Zhao, C. An experimental study on the optimization of drilling fluid in offshore gas hydrate formations. Natur. Gas Ind. 2019, 39, 104-109, (In Chinese with English abstract).

34. Zhao, X.; Qiu, Z.; Wang, M.; Huang, W.; Zhang, S. Performance Evaluation of a Highly Inhibitive Water-Based Drilling Fluid for Ultralow Temperature Wells. J. Energy Resour. Technol. 2017, 140, 012906. [CrossRef]

35. Parizad, A.; Shahbazi, K.; Tanha, A.A. Enhancement of polymeric water-based drilling fluid properties using nanoparticles. J. Pet. Sci. Eng. 2018, 170, 813-828. [CrossRef] 